\title{
Fabrication of working and counter electrodes on plastic substrates for flexible dye-sensitized solar cells
}

\author{
Yeong-Lin Lai ${ }^{1, *}$, Yeong-Kang Lai ${ }^{2}$, Chun-Yi Zheng ${ }^{1}$, Guo-Hui Xu ${ }^{1}$, Yi-Ming Wang ${ }^{1}$, and Shan-Ching Chen ${ }^{1}$ \\ ${ }^{1}$ Department of Mechatronics Engineering, National Changhua University of Education, Changhua 50007, Taiwan \\ ${ }^{2}$ Department of Electrical Engineering, National Chung Hsing University, Taichung 40227, Taiwan
}

\begin{abstract}
This paper presents the fabrication technologies related to flexible titanium-dioxide $\left(\mathrm{TiO}_{2}\right)$ working electrodes and graphite counter electrodes on plastic substrates for dye-sensitized solar cells (DSSCs). The DSSC on a plastic substrate had a sandwich structure consisting of a $\mathrm{TiO}_{2}$ working electrode, an electrolyte, and a graphite counter electrode. Nano-crystalline $\mathrm{TiO}_{2}$ powder, titanium (IV) bis (ammonium lactato) dihydroxide (TALH), de-ionized water (DI water), and Triton X-100 were added to the mixture of PDMS base and curing agents to form $\mathrm{TiO}_{2}$ colloids for the $\mathrm{TiO}_{2}$ working electrode. The material analysis of the $\mathrm{TiO}_{2}$ working electrode and the graphite counter electrode employed field-emission scanning electron microscopy (FE-SEM), atomic force microscopy (AFM), and X-ray diffraction (XRD). Nano-crystalline $\mathrm{TiO}_{2}$ powder was used to form the $\mathrm{TiO}_{2}$ working electrode. The surface characteristics of the $\mathrm{TiO}_{2}$ and graphite films were investigated herein. The low-cost fabrication technologies of the $\mathrm{TiO}_{2}$ working electrode and graphite counter electrode on the plastic substrate were clearly demonstrated.
\end{abstract}

\section{Introduction}

According to the BP Statistical Review of World Energy in 2017, the oil reserves/production ratios in North America, Europe/Eurasia, and the Middle East were 32.3, 24.9, and 69.9 years, respectively. As energy reserves decline while energy consumption increases globally, the energy situation continues to deteriorate [1]. In addition, the use of energy derived from the fossil fuels has caused serious climate problems, such as global warming and abnormal weather, as well as pollution and respiratory diseases.

In response to the energy and climate problems, research on renewable energy has become an urgent global topic. The renewable energy power sources include solar power, hydroelectric power, tidal power, wind power, etc. Among the renewable energy sources, solar power has great development potential and application in renewable energy.

Dye-sensitized solar cells (DSSCs) [2-28] offer numerous advantages compared to other types of solar cells. Firstly, the manufacturing processes of DSSCs are simple and do not need expensive vacuum equipment; sencondly, DSSCs have low material cost; thirdly, DSSCs can be flexible; and fourthly, DSSCs technology is environmentally friendly. Owing to their excellent advantages, DSSCs are promising for a wide range of applications; for instance, DSSCs can be utilized as the windows and glass curtains of buildings.

In this paper, the fabrication technologies of flexible $\mathrm{TiO}_{2}$ working and graphite counter electrodes for DSSCs were studied. The DSSCs adopted the flexible indium- tin-oxide PET (ITO-PET) plastic materials. The material analysis of $\mathrm{TiO}_{2}$ working and graphite counter electrodes were analyzed by field emission electron scanning microscopy (FE-SEM), atomic force microscopy (AFM), and X-ray diffraction (XRD). The low-cost manufacturing technology of $\mathrm{TiO}_{2}$ working and graphite counter electrodes of DSSCs was demonstrated.

\section{Structure and mechanism}

\subsection{Structure}

The structure and mechanism of a DSSC are shown in Fig. 1. A DSSC was composed of a working electrode, a counter electrode and an electrolyte between the working and counter electrodes, which were stacked into a sandwich structure.

The working electrode contained $\mathrm{TiO}_{2}$ film grown on a flexible PET plastic substrate with an indium tin oxide (ITO) conductive film. The energy absorption range of $\mathrm{TiO}_{2}$ is in the ultraviolet spectrum. When ultraviolet light is irradiated on the surface of $\mathrm{TiO}_{2}$, the electrons of the valence band are excited to the conduction band and produce electron-hole pairs. The working electrode mainly provided a dye adsorption area and a path of electron conduction. The working electrode needed to have a large surface area, high roughness, high porosity, high stability, and good adhesion to the substrate.

An electrolyte consisted of negatively charged iodide ions $\left(\mathrm{I}^{-}\right)$and triiodide ions $\left(\mathrm{I}_{3}{ }^{-}\right)$in organic solvents as a reduction-oxidation couple.

Corresponding author: yllai@,cc.ncue.edu.tw 


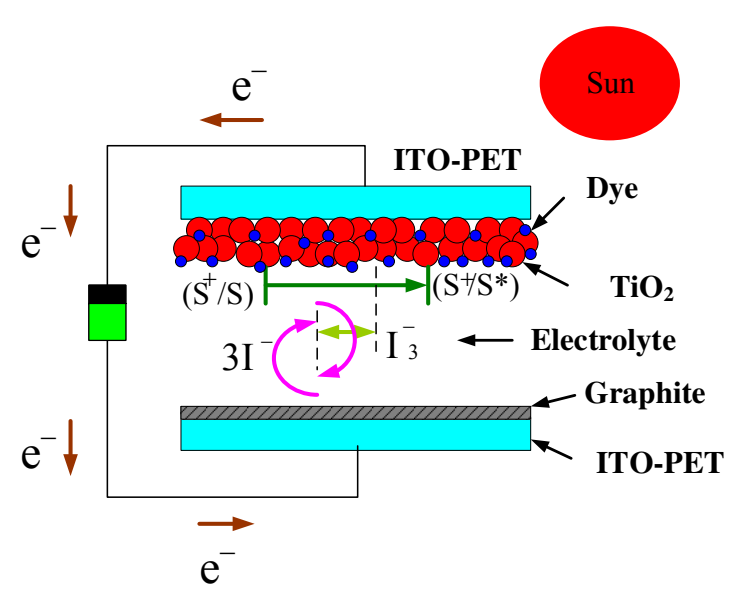

Fig. 1. Structure of dye-sensitized solar cell.

The graphite counter electrode had a graphite film grown on a flexible ITO-PET plastic substrate. Graphite was a useful counter electrode material due to its good conductivity. The counter electrode with regard to the reduction-oxidation reaction needed to have good catalytic properties, corrosion resistance, and low equivalent series resistance.

\subsection{Mechanism}

The mechanism regarding the DSSC is based on the processes of photoelectrochemistry, which include photoexcitation, electron injection, oxidation, and reduction, as follows [28]:

-Photoexcitation

The light irradiates the working electrode, and the dye molecules absorb photons and change from the ground state $(\mathrm{S})$ to the excited state $\left(\mathrm{S}^{*}\right)$ :

$$
\mathrm{S}+h v \rightarrow \mathrm{S}^{*}
$$

-Electron injection and oxidation

The electrons on the excited state dye molecules are injected into the conduction band of the $\mathrm{TiO}_{2}$ semiconductor. At this moment, the dye molecules are present in an oxidized state $\left(\mathrm{S}^{+}\right)$:

$$
\mathrm{S}^{*} \rightarrow \mathrm{e}^{-}\left(\mathrm{TiO}_{2}\right)+\mathrm{S}^{+}
$$

-Reduction

The electrons on the conduction band of the $\mathrm{TiO}_{2}$ semiconductor are conducted into the transparent conductive film. The electrons on the transparent conductive film are then conducted to the counter electrode via an external circuit. The triiodide ions in the electrolyte obtain electrons from the counter electrode and convert into iodide ions:

$$
\mathrm{I}_{3}^{-}+2 \mathrm{e}^{-} \rightarrow 3 \mathrm{I}^{-}
$$

The oxidized state dye molecules react with the iodide ions in the electrolyte and convert to ground state dye molecules. The iodide ions lose electrons and then convert it into triiodide ions:

$$
2 \mathrm{~S}^{+}+3 \mathrm{I}^{-} \rightarrow 2 \mathrm{~S}+\mathrm{I}_{3}^{-}
$$

The photoelectrochemistry through the photoexcitation, electron injection, oxidation, and reduction achieves the required complete loop for electron conduction.

\section{Experimental}

The fabrication of DSSCs, including the PDMS, working electrode, counter electrode, and electrolyte processes, was conducted.

\subsection{PDMS}

The PDMS used was the Sylgard 184 silicone from Dow Corning Corp. The PDMS was made up of a base agent and a curing agent. The 10:1 weight ratio of the base agent to the curing agent was adopted. The physical properties of the PDMS were determined by the ratio.

\subsection{Working electrode}

The $\mathrm{TiO}_{2}$ colloid for the working electrode was formed by nano-crystalline $\mathrm{TiO}_{2}$ powder, titanium (IV) bis (ammonium lactato) dihydroxide (TALH), de-ionized water (DI water), Triton X-100, a PDMS base agent, and a PDMS curing agent, indicated by $\mathrm{A}, \mathrm{B}, \mathrm{C}, \mathrm{D}, \mathrm{E}$, and F, respectively. In this work, the weight ratio of the nanocrystalline $\mathrm{TiO}_{2}$ powder, TALH, DI water, and Triton X100 was kept at 2:10:5:1. The weight ratio of the PDMS base and curing agents, E:F, was kept at 10:1. The weight ratios of the PDMS base and curing agents were varied so that the weight ratios of $A: B: C: D: E$ were changed from $2: 10: 5: 1: 1$ to $2: 10: 5: 1: 5$.

In this work, the conditions of the $\mathrm{TiO}_{2}$-PDMS mixtures studied are listed in Table 1 . There were three conditions. In the first condition, the nano-crystalline $\mathrm{TiO}_{2}$-PDMS mixture was mixed with 0.2-g $\mathrm{TiO}_{2}$ powder, 1-g TALH, 0.5-g DI water, 0.1-g Triton X-100, a 0.1-g PDMS base agent, and a $0.01-\mathrm{g}$ curing agent. In the second condition, the nano-crystalline $\mathrm{TiO}_{2}$-PDMS mixture was mixed with $0.2-\mathrm{g} \mathrm{TiO}_{2}$ powder, 1 -g TALH, 0.5-g DI water, 0.1-g Triton X-100, a 0.3-g PDMS base agent, and a 0.03 -g curing agent. In the third condition, the nano-crystalline $\mathrm{TiO}_{2}$-PDMS mixture was mixed with 0.2-g $\mathrm{TiO}_{2}$ powder, 1-g TALH, 0.5-g DI water, 0.1g Triton X-100, a 0.5-g PDMS base agent, and a 0.05-g curing agent.

Table 1. Conditions of TiO2-PDMS mixtures.

\begin{tabular}{|c|c|c|c|c|c|c|}
\hline & $\mathrm{A}$ & $\mathrm{B}$ & $\mathrm{C}$ & $\mathrm{D}$ & $\mathrm{E}$ & $\mathrm{F}$ \\
\hline & $\begin{array}{c}\mathrm{TiO}_{2} \\
(\mathrm{~g})\end{array}$ & $\begin{array}{c}\mathrm{TALH} \\
(\mathrm{g})\end{array}$ & $\begin{array}{c}\mathrm{DI} \\
\text { water } \\
(\mathrm{g})\end{array}$ & $\begin{array}{c}\text { Triton } \\
\text { X- } \\
100 \\
(\mathrm{~g})\end{array}$ & $\begin{array}{c}\text { PDMS } \\
\text { base } \\
\text { agent } \\
(\mathrm{g})\end{array}$ & $\begin{array}{c}\text { PDMS } \\
\text { curing } \\
\text { agent } \\
(\mathrm{g})\end{array}$ \\
\hline $\mathrm{I}$ & 0.2 & 1 & 0.5 & 0.1 & 0.1 & 0.01 \\
\hline $\mathrm{II}$ & 0.2 & 1 & 0.5 & 0.1 & 0.3 & 0.03 \\
\hline III & 0.2 & 1 & 0.5 & 0.1 & 0.5 & 0.05 \\
\hline
\end{tabular}


The uniform $\mathrm{TiO}_{2}$-PDMS mixture without air bubbles was obtained by gently stirring with a glass rod for $30 \mathrm{~min}$. The active region of DSSC was surrounded by Scotch-tape $(3 \mathrm{M})$. The $\mathrm{TiO}_{2}$-PDMS mixture was coated by the doctor blade technique. The tape was then removed and the electrode was heated at $70{ }^{\circ} \mathrm{C}$ for 30 min for curing. The $\mathrm{TiO}_{2}$-PDMS electrode was dipped in the N719 dye for $24 \mathrm{~h}$.

\subsection{Counter electrode}

The graphite colloid for the counter electrode was formed by $0.6-\mathrm{g}$ graphite powder, a 3-g PDMS base agent, and a 0.3 -g PDMS curing agent. The weight ratio of the graphite powder, PDMS base agent, and PDMS curing agent was kept at 2:10:1.

\subsection{Electrolyte}

An electrolyte was made by iodine $\left(\mathrm{I}_{2}\right)$, potassium iodide (KI), and propylene carbonate.

At first, a beaker contained $20 \mathrm{ml}$ (about $23.4 \mathrm{~g}$ by weight) of propylene carbonate. Then, 0.254-g iodine and 1.66-g potassium iodide were added. The beaker containing the mixer was vibrated by an ultrasonic vibrator for $30 \mathrm{~min}$ twice. Finally, the electrolyte was then formed.

\section{Results and discussion}

In this work, the SEM analysis was conducted by a JEOL JSM-6700F FE-SEM. The FE-SEM analysis of the nano-crystalline $\mathrm{TiO}_{2}$ powder and graphite powder were studied. Fig. 2 shows the surface morphology of the nano-crystalline $\mathrm{TiO}_{2}$ powder. The surface morphology of the graphite powder is shown in Fig. 3. The $\mathrm{TiO}_{2}$ powder was also analyzed using the XRD. The nano-crystalline $\mathrm{TiO}_{2}$ powder was observed. Fig. 4. shows the XRD characteristics of the $\mathrm{TiO}_{2}$ powder. Two mineral forms of $\mathrm{TiO}_{2}$ : anatase and rutile titanium dioxide, were obtained.

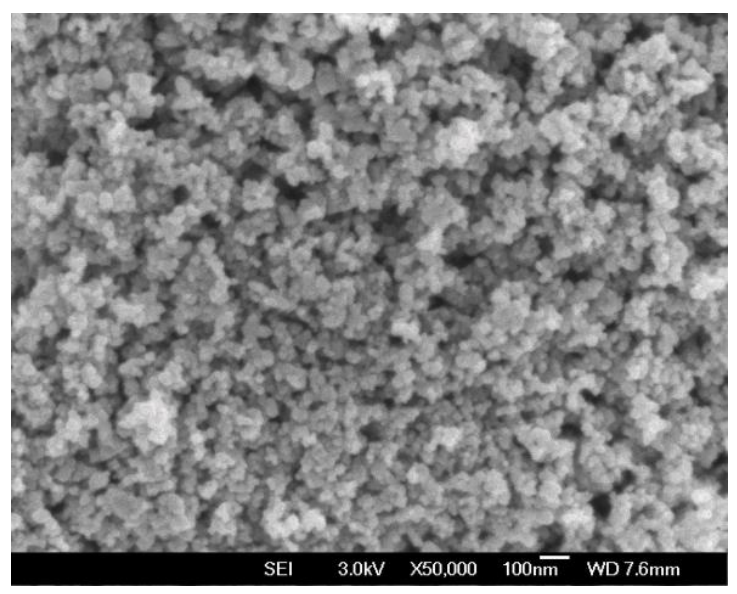

Fig. 2. Surface morphology of nano-crystalline $\mathrm{TiO}_{2}$ powder.

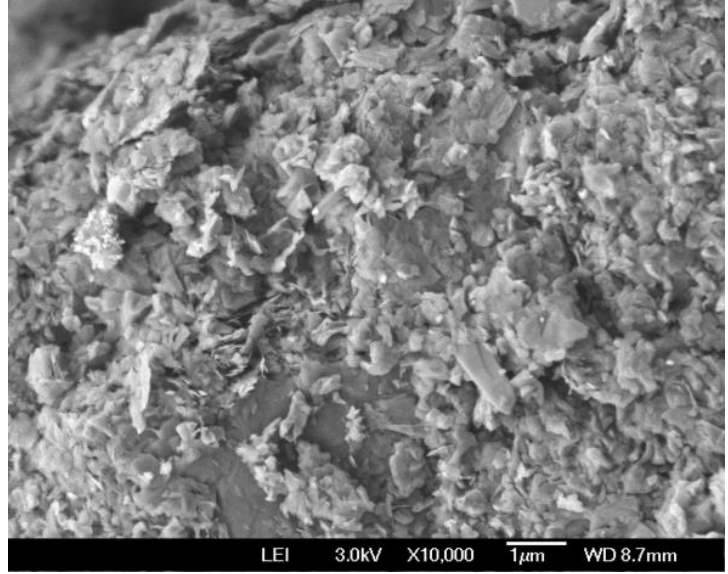

Fig. 3. Surface morphology of graphite powder.

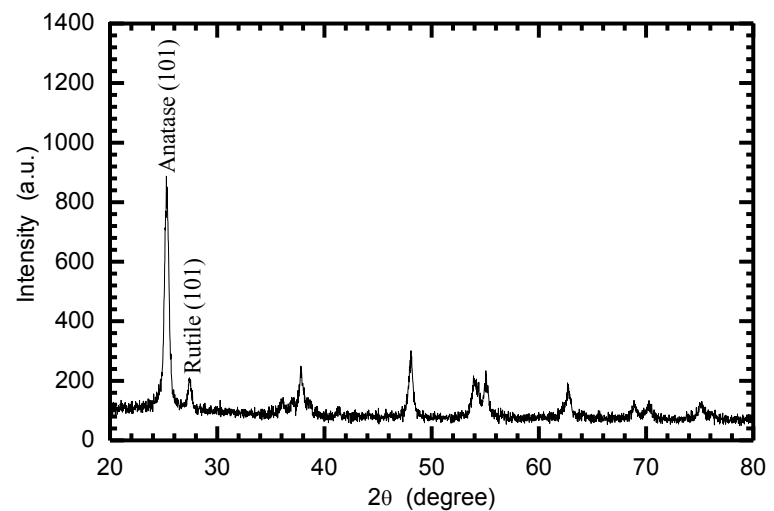

Fig. 4. XRD characteristics of $\mathrm{TiO}_{2}$ powder.

The transmission property of the flexible ITO-PET substrate was analyzed by a spectrum analyzer. The transmission property of the flexible ITO-PET substrate coated with the PDMS was also studied. Fig. 5 shows the transmission characteristics of the flexible ITO-PET substrate and the ITO-PET substrate coated with the PDMS. The ITO-PET substrate had better transmission characteristics than the ITO-PET/PDMS substrate.

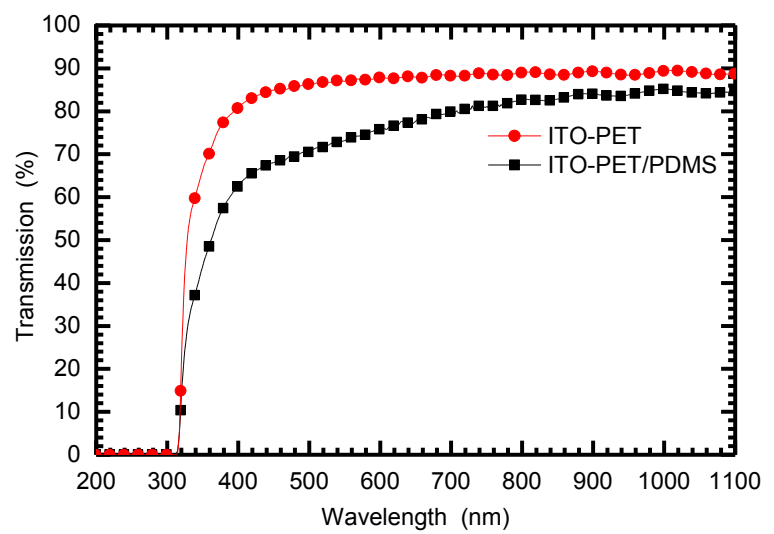

Fig. 5. Transmission characteristics of ITO-PET and ITOPET/PDMS substrates. 


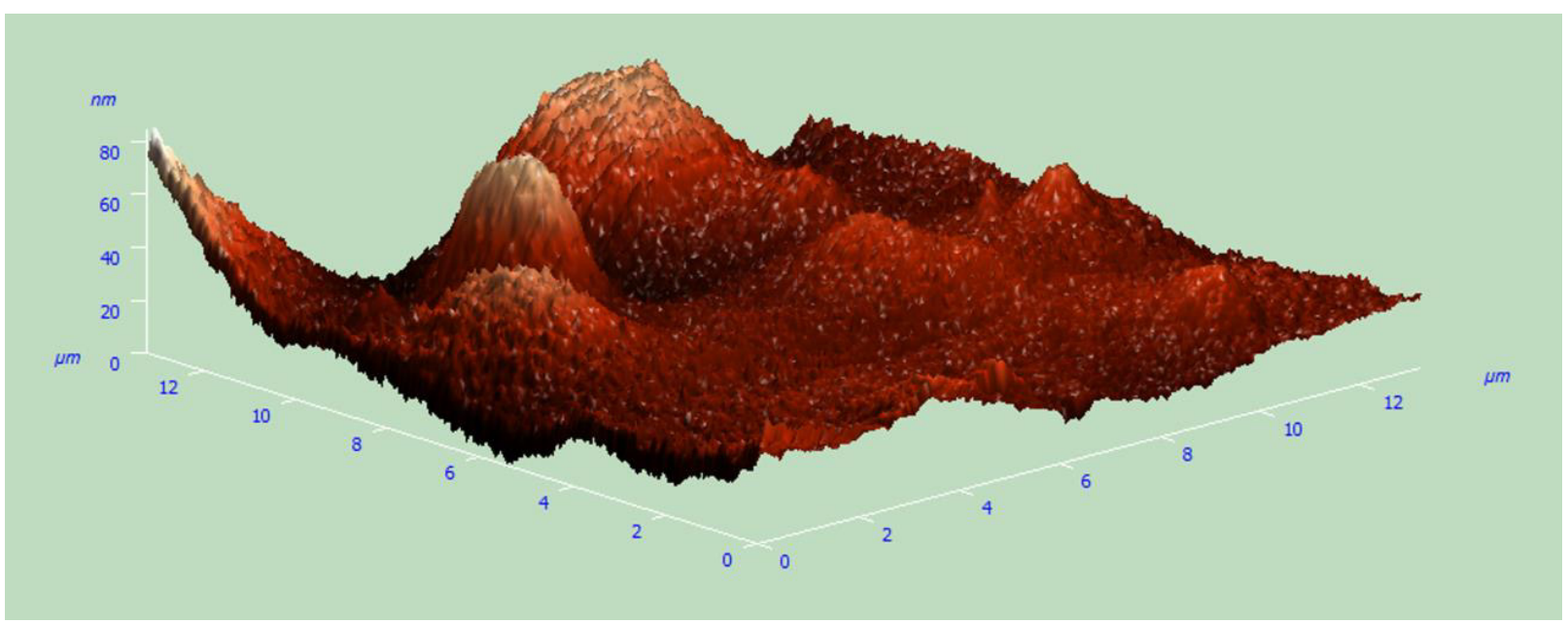

Fig. 6. AFM analysis result of graphite colloid.

The surface analysis of the flexible ITO-PET substrate was conducted by an NT-MDT Solver P47 AFM. The AFM analysis of the graphite counter electrode was also investigated. Fig. 6 shows the AFM analysis result of the graphite colloid.

The surface analysis of the $\mathrm{TiO}_{2}$ working electrod was conducted by the FE-SEM. The surface observation of the $\mathrm{TiO}_{2}$ colloid with the $\mathrm{A}: \mathrm{B}: \mathrm{C}: \mathrm{D}: \mathrm{E}$ ratio of 2:10:5:1:1 is shown in Fig. 7. The $\mathrm{TiO}_{2}$-PDMS colloid had a porous surface.

Fig. 8 shows the fabricated flexible DSSC consisting of a flexible IOT-PET substrate, a $\mathrm{TiO}_{2}$-PDMS working electrode, a graphite-PDMS electrode, and an electrolyte.

The investigation of the electrical characteristics of the $\mathrm{TiO}_{2}$ colloids was carried out. Fig. 9 shows the electrical characteristics of the DSSCs with different $\mathrm{A}: \mathrm{B}: \mathrm{C}: \mathrm{D}: \mathrm{E}$ ratios.

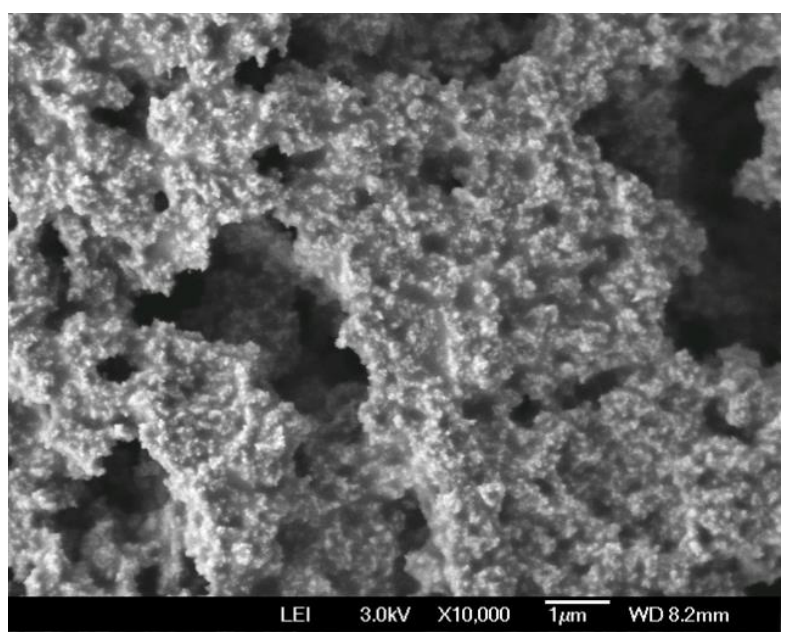

Fig. 7. Surface morphology of $\mathrm{TiO}_{2}-\mathrm{PDMS}$ colloid.

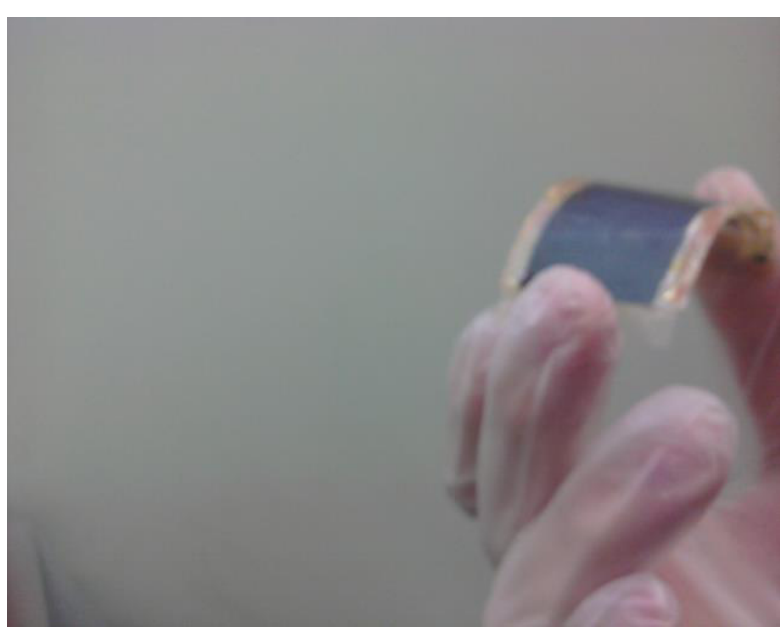

Fig. 8. Fabricated flexible DSSC.

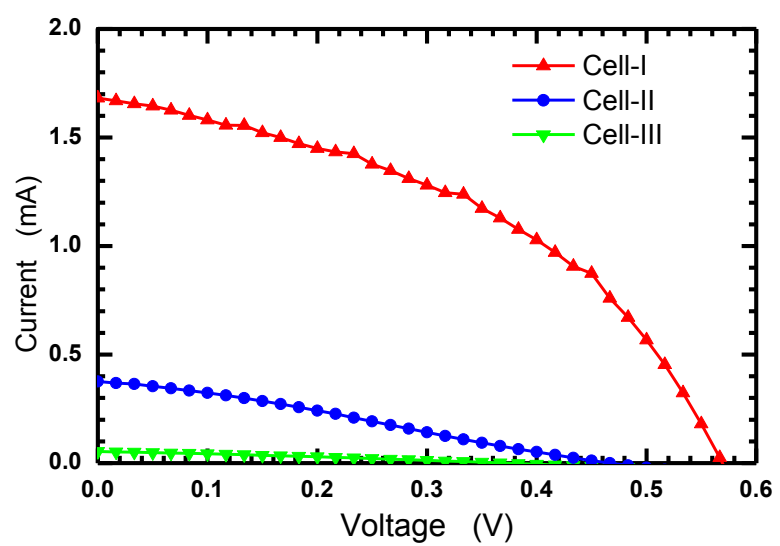

Fig. 9. Electrical characteristics of DSSCs with different A:B:C:D:E ratios. 
The DSSCs corresponding to the A:B:C:D:E ratios of $2: 10: 5: 1: 1,2: 10: 5: 1: 3$, and $2: 10: 5: 1: 5$ were indicated by Cell-I, Cell-II, and Cell-III, respectively. It was found that the increase in the $\mathrm{TiO}_{2}$ percentage of the colloid enhanced the current and voltage characteristics. The DSSC with the A:B:C:D:E ratio of 2:10:5:1:1 exhibited the best current and voltage characteristics.

\section{Conclusion}

The flexible DSSCs on the ITO-PET substrates were fabricated. The $\mathrm{TiO}_{2}$ and graphite colloids were fabricated for the working and counter electrodes of the DSSCs, respectively. The $\mathrm{TiO}_{2}$ colloid was made from the nano-crystalline $\mathrm{TiO}_{2}$ powder, TALH, DI water, Triton X-100, PDMS base agent, and PDMS curing agent. The graphite colloid was made from the graphite powder, PDMS base agent, and PDMS curing agent. The transmission characteristics of the ITO-PET and ITOPET/PDMS substrates were studied. The fabrication techniques of the flexible $\mathrm{TiO}_{2}$ working and graphite counter electrodes on the plastic substrate demonstrated the potential for flexible green energy applications.

\section{Acknowledgment}

This work was supported in part by the Ministry of Science and Technology of Taiwan, R.O.C. under Contracts MOST 1042221-E-018-016, MOST 105-2218-E-018-001, MOST 1062218-E-018-002, and MOST 106-2218-E-018-003.

\section{References}

1. BP Statistical Review of World Energy June 2017.

2. Y.L. Lai, L.W. Chen, C.-H. Chen, Appl. Mechanics Mater., 865, 54 (2017)

3. L. W. Veldhuizen, Y. Kuang, R. E. I. Schropp, Sol. Energy Mater. Sol. Cells, 158, 209 (2016)

4. M. Grätzel, J. Photochem. \& Photobio. A: Chem., 164, 3 (2004)

5. K. Kalyanasundaram, M. Grätzel, Coord Chem. Rev., 177, 347 (1998)

6. Y.L. Lai, L.Y. Tang, J. Precis. Machinery Manuf. Technol., 6, 1 (2016)

7. H. C. Weerasinghe, F. Huang, Y.B. Cheng, Nano Energy, 2, 2 (2013)

8. J. Huang, S. Varlamov, J. Dore, J. S. Yun, M. A. Green, Sol. Energy Mater. Sol. Cells, 132, 282 (2015)

9. W. A. Badawy, J. Adv. Res., 6, 123 (2015)

10. Y.L. Lai, S.H. Chen, J.-H. Lu, J.-S. Ting, T.Y. Tsai, Lect. Notes Electr. Eng., 234, 975 (2013)

11. J. N. Clifford, E. Martínez-Ferrero, A. Viterisi, E. Palomares, Chem. Soc. Rev., 40, 3 (2011)

12. S. Kim, D.M. Geum, M.S. Park, C. Z. Kim, W. J. Choi, Sol. Energy Mater. Sol. Cells, 141, 372 (2015)

13. M. S. Suait, M. Y. A. Rahman, A. Ahmad, Solar Energy, 115, 452 (2015)

14. Goetzberger, C. Hebling, H. W. Schock, Mater. Sci. Eng.: R: Reports 40, 1 (2003)
15. D. M. Chapin, C. S. Fuller, G. L. Pearson, J. Appl. Phys., 25, 676 (1954)

16. S. Y. Chae, S. J. Park, O.S. Joo, B. K. Min, Y. J. Hwang, Sol. Energy, 135, 821 (2016)

17. K. Hara, K. Sayama, Y. Ohga, A. Shinpo, S. Suga, H. Arakawa, Chem. Comm., 569 (2001)

18. K. Srikanth, Md. M. Rahman, H. Tanaka, K.M. Krishna, T. Soga, M. K. Mishra, T. Jimbo, M.Umeno, Sol. Energy Mater. \& Sol. Cells, 65, 171 (2001)

19. J. M. Nunzi, C. R Phys., 3, 523 (2002)

20. S. Mozaffari, M. R. Nateghi, M. B. Zarandi, Renew. Sustainable Energy Rev., 71, 675 (2017)

21. S. Sharma, B. Siwach, S.K. Ghoshal, D. Mohan, Renew. Sustainable Energy Rev., 70, 529 (2017)

22. I. Kontos, A. G. Kontos, D. S. Tsoukleris, M. C. Bernard, N. Spyrellis, P. Falaras, J. Mater. Proce Tech., 196, 243 (2008)

23. V. Kislyuk, O. Dimitriev, J. Nanosci, Nanotechnol., 8, 1 (2008)

24. H. Lindström, A. Holmberg, E. Magnusson, S. E. Lindquist, L. Malmqvist, A. Hagfeldt, Nano Letters, 1, 97 (2001)

25. Y.L. Lai, Y.H. Huang, Lect. Notes Electr. Eng., 234, 987 (2013)

26. W. Kubo, T. Kitamura, K. Hanabusa, Y. Wada, S. Yanagida, Chem. Comm., 374 (2002)

27. H. Tsubomura, M. Matsumura, Y. Nomura, T. Amamiya, Nat., 261, 402 (1976)

28. B. O’Regan, M. Grätzel, Nat., 353, 737 (1991) 